\title{
Deflection Design of Joinery Melamine Shelf in Cabinet Furniture
}

\author{
LIU Yun ${ }^{1, a}$, SHI Shuang ${ }^{2, b}$, SHENG Liming ${ }^{1, c}$ \\ ${ }^{1}$ College of Furniture \& Industrial Design, NFU,CHINA \\ ${ }^{2}$ College of Civil Engineeringr, NFU,CHINA

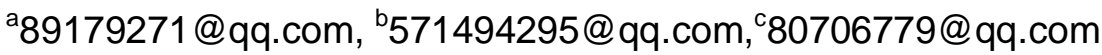

Keywords: Melamine veneer joinery shelf; Bookcase shelf; Deflection

Abstract. The center point deflection of melamine veneer joinery shelf is calculated through orthogonal isotropic deflection equation, and is verified on the basis of the experiment. Then, the calculation formula of the deflection value of melamine veneer joinery shelf that satisfies the practical production is obtained, which can enable the designers to master how to design the melamine veneer joinery shelf reasonably.

\section{Introduction}

Joinery melamine board (melamine veneer joinery board), also called double veneer board or ecological board, is a kind of special plywood with real wood core. It has significant environmental effect, is a common ideal material of furniture production, and has been widely used for plate type bookcase. Shelf is one of the essential components for bookcase. For a long time, the design of bookcase shelf is based on experience and is not quite scientific. Especially when people choose new material for making furniture, it tends to cause the material waste, or make furniture lose the reliability. Shelf bending deformation problem is one example. According to the mechanical properties of materials, the shelf deflection design through the principle of mechanics can help to reduce the consumption of furniture materials, reduce the cost of furniture, and also help the correct and reasonable choice of new materials, and guarantee the reliability and security of furniture use. The furniture shelf basically can be divided into three forms, namely, four edge bearing, three edge bearing and two edge bearing (referred to as simply-supported one, being the most common form). The shelf with different numbers of edge bearing has very big differences in bending deformation.

General furniture shelf belongs to the category of thin plate in the mechanics, and the research theory also belongs to the theory of thin plates. From the perspective of mechanical properties of joinery melamine board, it basically belongs to the isotropic material on $\mathrm{x}-\mathrm{y}$ plane. Besides, from the aspect of shelf bearing load, it unusually is the uniformly distributed load of simply supported form at two sides. By taking bookcase shelf as an example, the paper discusses a kind of simplified deflection-based furniture shelf design method. Based on the analysis of the stress state of shelf, the deflection design mathematical model is deduced and used to represent the relationship between thickness (H), span (L), material, structure form and shelf load of the shelf, serving as a the design material for designers' reference.

\section{Principle of Shelf Deflection Model}

Structure Form of the Shelf. According to the structure characteristics and mechanical properties of the commonly-used shelf in current furniture, shelf can be divided into two categories (A and B ). Category A can be divided into A-1 type (horizontal shelf parallel arrangement and palisade core 
layer double veneer) and A-2 type (vertical shelf parallel arrangement and palisade core layer double veneer). Besides, Category B can be divided into B-1 type (solid core structure board or solid core veneer which veneer plate has a little influence on the elastic modulus) and B-2 type (solid core veneer which veneer plate has great influence on the elastic modulus).

Design Basis of Shelf Deflection.According to the relevant provisions of IS07170, cabinet furniture shelf load is divided into 4 levels (Table 1). For the shelf which is used to store decoration and light items, choose level 1 load; for the shelf which is used to store lighter items such as textile and food, choose level 2 load; for the shelf which is used to store medium weight of items such as small size book and TV, choose level 3 load; for the shelf which is used to store heavy items such as large size book, choose level 4 load.

\begin{tabular}{cccc} 
& Table 1 & Load on Shelf $\mathrm{q}\left(\mathrm{Kgf} / \mathrm{dm}^{2}\right)$ \\
\hline Level & 1 & 2 & 3 \\
\hline Load & 1 & 1.5 & 2
\end{tabular}

Mathematical Model Derivation of Shelf Deflection Design.When shelf is full of goods, the load its bears can be approximately considered as uniformly distributed load; when the ends of the shelf have no bending moment constraints, it is the most unfavorable for stiffness of the shelf. For the sake of calculation convenience and reliability of shelf, the mathematical model of shelf stiffness design is derived under the conduction that uniformly distributed load simply supported beam which both ends have no bending constraint. The mathematical deflection model is shown in Figure 1:

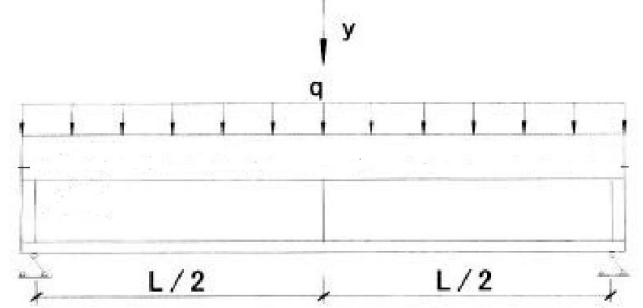

Figure 1 Uniformity Distributed Load Model

For the experiment, the orthogonal synthetic material melamine veneer joinery board can be regarded as B-type 1 board. By using the relevant design manual, we can obtain the reasoning process of deflection expression:

$$
\begin{aligned}
\omega(\mathrm{x})=\theta_{0} x+ & \frac{1}{B_{2}}-\beta_{1} m_{1} \frac{x^{2}}{2}+\beta_{1}\left(\frac{q l}{2}+\frac{m_{1}-m_{3}}{L}\right) \frac{x^{3}}{6}-\beta_{1} q \frac{x^{4}}{24} \\
& +\left\|_{L 1}\left(\beta_{1}-1\right) q \frac{\left(x-L_{1}\right)^{4}}{24}-\right\|_{L 1} \frac{\left(\beta_{1}-1\right) q L^{2}}{2} \times \frac{\left(x-L_{1}\right)^{3}}{6} \\
& -\left\|_{L 1+L 2} \frac{\left(\beta_{3}-1\right) q l_{2}}{2} \frac{\left(x-l_{1}-l_{2}\right)^{3}}{24}-\right\|_{L 1+L 2}\left(\beta_{3}\right. \\
& -1) q \frac{\left(x-l_{1}-l_{2}\right)^{4}}{24}
\end{aligned}
$$

In the formula $(1), \|_{L_{1}}()$ indicates the it works when $x>L_{1}$; the rest may be deduced by analogy. In the formula, for the plus-minus sign of $\mathrm{q}, \mathrm{m}_{1}$ and $\mathrm{m}_{3}$, the actual direction and the same direction with the picture is plus sign; the upwards deflection is plus sign; rotating angle $\theta$ takes counterclockwise direction as plus sign.

To solve the maximum of $\omega$, we can get one variable cubic equation. After solving it, we can obtain the $\mathrm{x}$ value of the maximum point of deflection and then put it into the formula.

The expression of deflection at the mid-span L/2 is as follows: 


$$
\begin{aligned}
\omega\left(\frac{L}{2}\right)=\theta_{0} \frac{L}{2} & +\frac{1}{B_{2}}\left\{-\beta_{1} m_{1} \frac{L^{2}}{8}+\beta_{1}\left\langle\frac{q L}{2}+\frac{m_{1}-m_{3}}{L}\right\rangle \times \frac{L^{3}}{48}-\beta_{1} \frac{q L^{4}}{384}\right. \\
& \left.+\left(\beta_{1}-1\right) q\left[\frac{\left(L-2 L_{1}\right)^{4}}{384}-\frac{L_{2}\left(L-2 L_{1}\right)^{3}}{96}\right]\right\}
\end{aligned}
$$

When $=1$, the above formula will be reduced to the calculation formula of uniformly distributed load deflection of simply supported beam.

The equation is $\omega=\frac{q x}{24 E I}\left(l^{3}-2 l x^{2}+x^{3}\right)$

The formula is $\omega=\frac{5 q l^{4}}{384 E I}$

"I" indicates the moment of inertia; the test requires a rectangular section, so the required moment of inertia is as follows:

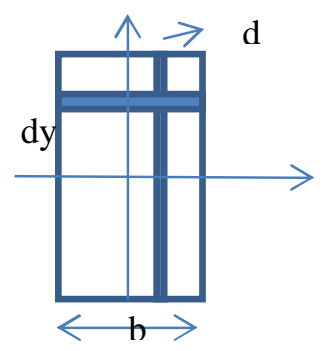

$$
\mathrm{dA}=\text { bdy }
$$

Then, the cross sectional moment of inertias is as follows:

$$
\mathrm{I}=\int_{A} y^{2} d A=\int_{-\frac{h}{2}}^{\frac{h}{2}} y^{2} b d y=\frac{b h^{3}}{12}
$$

In the formula (2) and (3), q denotes the load of the per unit area of shelf $\left(\mathrm{N} / \mathrm{m}^{2}\right)$; E indicates the anti-bending elasticity modulus of melamine veneer joinery board $(\mathrm{MPa}) ; l$ denotes the span of shelf $(\mathrm{mm})$; $b$ denotes the width of shelf $(\mathrm{mm})$; $h$ indicates the thickness of melamine veneer joinery board (mm).

\section{Experiment}

Preparation of Experiment Materials. Test materials are two pieces of the same size of solid glue three layers of joinery board. The wood assortment of its core board is poplar. The total thickness is $17 \mathrm{~mm}$; the size is $630 \mathrm{~mm} \times 240 \mathrm{~mm}$; the plate is sawed along the length direction of core board wood. Supporting at two sides takes up $15 \mathrm{~mm}$. The actual span of the board is $600 \mathrm{~mm}$; the measured anti-bending elasticity module is $7420 \mathrm{Mp}$.For the deflection testing instrument, we adopted high-precision electronic digital display micrometer of Jurong brand produced in Ningbo, Zhejiang. We made the test device, as shown in Figure 2:
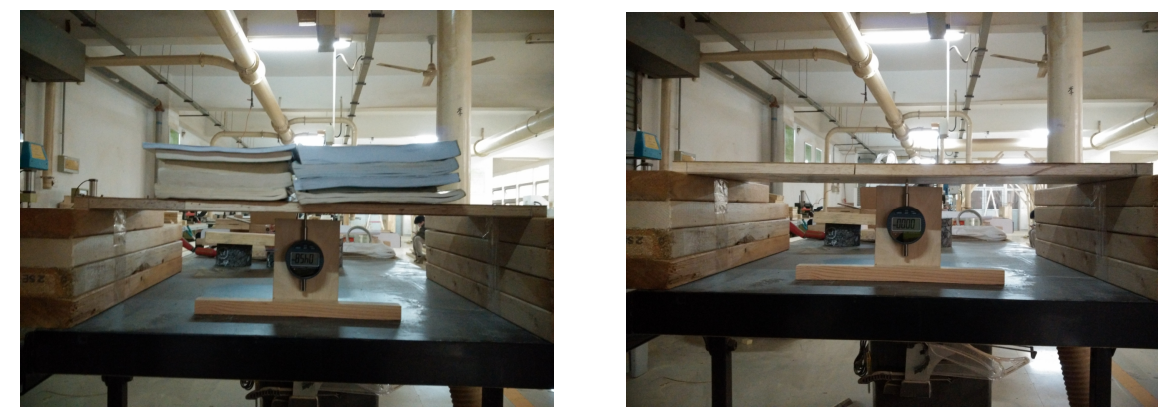

Figure 2 Simple Deflection Testing Device 
Experiment Methods.Progressively increase the uniformed load by taking book weight as the load and $1 \mathrm{~kg}$ as the unit of load to the test panel, add one each time and record the instantaneous deflection deformation when the dial indicator value keeps stable in $1 \mathrm{~min}$.

Analysis of Experiment Data.According to Table 1, the bookcase shelf is mainly used to store heavy items such as books, so we selected level 4 load $\left(2.5 \mathrm{Kgf} / \mathrm{dm}^{2}\right)$.

The maximum load in the experiment: $Q_{\max } \leq 2.5 \mathrm{Kgf} / \mathrm{dm}^{2}$ x $6 \mathrm{dm} \times 2.4 \mathrm{dm}=36 \mathrm{Kgf}$.

Thus, the load below $36 \mathrm{Kg}$ is selected.

Because the test panel is relatively thin (17 mm in thickness), so we progressively increased the test load from $1 \mathrm{~kg}$ to $10 \mathrm{~kg}$ by adding $1 \mathrm{Kg}$ each time. Then, the instantaneous variables are measured, and the following data are got, as shown in Table 2.

Table 2 Deflection Value Variation of Melamine Veneer Joinery Shelf under Uniform Load

\begin{tabular}{ccccccccccc}
\hline Payload & $1 \mathrm{Kg}$ & $2 \mathrm{Kg}$ & $3 \mathrm{Kg}$ & $4 \mathrm{Kg}$ & $5 \mathrm{Kg}$ & $6 \mathrm{Kg}$ & $7 \mathrm{Kg}$ & $8 \mathrm{Kg}$ & $9 \mathrm{Kg}$ & $10 \mathrm{Kg}$ \\
\hline Board1 & 0.081 & 0.163 & 0.262 & 0.362 & 0.458 & 0.587 & 0.665 & 0.792 & 0.857 & 0.968 \\
Board2 & 0.078 & 0.157 & 0.244 & 0.339 & 0.443 & 0.568 & 0.664 & 0.794 & 0.867 & 0.990 \\
\hline
\end{tabular}

\section{Experimental Verification of Shelf Deflection Design Mathematical Model.}

Shelf deflection design and production is based on the aforementioned mathematical model, load condition and plank characteristics. In order to validate the validity of the model, it is put into the model for calculation according to the test load condition and plate features. The calculated results are compared with experimental results to prove the validity of the model.

Formula of deflection mathematical mode (2) $\quad \omega=\frac{5 q l^{4}}{384 E I}$

in which (3) $I=\frac{b h^{3}}{12}$ and $E=7420 \mathrm{Mp}$,By placing panel and loading condition,

$$
\begin{aligned}
& Q_{F}=1,2,3 \ldots 10,15 \mathrm{Kg}, \\
& b=0.24 m, h=0.017 \mathrm{~m}, l=0.6 \mathrm{~m}, \\
& \text { Plate area } S=0.63 \mathrm{~m} \times 0.24 \mathrm{~m}=0.1512 \mathrm{~m}^{2}
\end{aligned}
$$

$10 \mathrm{~kg}$ is selected as the calculated uniform load, and $\omega^{\prime}{ }_{10}$ is calculated according to mathematical model formula(2) and (3)

$$
\begin{aligned}
& \omega_{10}^{\prime}=\frac{5 \times \frac{10 \times 9.8}{0.1512} \times 0.6 \times 0.6^{4}}{384 \times 7420 \times 10^{6} \times \frac{0.24 \times 0.017^{3}}{12}}=0.901 \times 10^{-3} \mathrm{~m} \\
& \omega_{10}^{\prime}=0.901 \mathrm{~mm}
\end{aligned}
$$

The actually-measured deflection in the experiment is

$$
\omega_{10}^{1}=0.968 \mathrm{~mm}, \omega_{10}^{2}=0.867 \mathrm{~mm}
$$

$$
\begin{aligned}
\text { Relative error } \quad \theta_{10}^{1} & =\frac{0.968-0.901}{0.901}=7.4 \% \\
\theta_{10}^{2} & =\frac{0.901-0.867}{0.901}=3.8 \%
\end{aligned}
$$

Other loads are compared through the same calculation, the following Table 3 can be concluded: 
Table 3 Data comparison of the Deflection Calculation and Measured about the Shelf

\begin{tabular}{|c|c|c|c|c|c|c|c|c|}
\hline Load & $(\mathrm{Kg})$ & $\begin{array}{l}\text { Uniformly } \\
\text { Distributed } \\
\text { load }(\mathrm{N} / \mathrm{m})\end{array}$ & $\begin{array}{l}\text { Measured } \\
\text { Deflection } 1 \\
(\mathrm{~mm})\end{array}$ & $\begin{array}{l}\text { Theoretical } \\
\text { Value } \\
(\mathrm{mm})\end{array}$ & Error $(\%)$ & $\begin{array}{l}\text { Measured } \\
\text { Deflection } 2 \\
(\mathrm{~mm})\end{array}$ & $\begin{array}{l}\text { Theoretical } \\
\text { Value } \\
(\mathrm{mm})\end{array}$ & Error $(\%)$ \\
\hline & 1 & 38.89 & 0.08 & 0.09 & 11.11 & 0.078 & 0.09 & 13.33 \\
\hline & 2 & 77.78 & 0.163 & 0.18 & 9.44 & 0.157 & 0.18 & 12.78 \\
\hline & 3 & 111.67 & 0.262 & 0.258 & 1.55 & 0.244 & 0.258 & 5.43 \\
\hline & 4 & 150.56 & 0.362 & 0.348 & 4.02 & 0.339 & 0.348 & 2.87 \\
\hline & 5 & 184.45 & 0.458 & 0.427 & 7.26 & 0.443 & 0.427 & 3.74 \\
\hline & 6 & 223.24 & 0.587 & 0.517 & 13.54 & 0.568 & 0.517 & 9.86 \\
\hline & 7 & 263.23 & 0.665 & 0.609 & 9.85 & 0.664 & 0.609 & 9.03 \\
\hline & 8 & 301.12 & 0.792 & 0.697 & 13.63 & 0.794 & 0.697 & 13.92 \\
\hline & 9 & 340.01 & 0.857 & 0.787 & 8.89 & 0.867 & 0.787 & 10.16 \\
\hline & 10 & 388.9 & 0.968 & 0.901 & 7.40 & 0.991 & 0.901 & 9.99 \\
\hline
\end{tabular}

The relative error of deflection under each load is within $14 \%$ (See the calculation and validation process for reference).

Visibly, for melamine veneer joinery, deflection equation accords with the actual situation.

\section{Conclusions}

Currently, because of the shortage of wood resources, and the mature development of man-made board industry, the furniture made of melamine veneer joinery occupies larger proportion, and the shelf deflection design is extremely important for cabinet furniture. In design, most of cabinet shelf is $800 \sim 900 \mathrm{~mm}$ in span and $15 \sim 22 \mathrm{~mm}$ in thickness. If melamines veneer joinery board is used as the bookcase shelf, it can be designed by referring to the above mentioned mathematical model under the allowable load, directly putting the dimensions of the required shelf into formula, analyzing whether the designed shelf deflection can meet the requirements. Deflection design on shelf, therefore, may also raise mechanics performance requirement for furniture material, and promote the development of furniture material industry.

\section{Acknowledgements}

This work was financially supported by the National Social Science Foundation (15XGL027), PAPD(A project Funded by the Priority Academic Program Development of JiangSu Higher Education Institutions), Ningde normal university scientific research funding projects(2014Q01) .

\section{References}

[1] Lu Xiaoning, Yi Xianghua and Zhang Zengbia:China Wood Industry Vol. 13 NO.1 (1999), p. 6

[2] Yu Songbao:Journal of Northeast Forestry University Vol.15 NO.2(1987),p.74

[3] Guan Huiyuan:Furniture NO.80(1994),p.4

[4] Ziren Ando:,China Wood Industry Vol.35 NO.6(1980),p.16

[5]Dong Yuku,Yu Songbao:Furniture NO.41(1988),p.4 